\title{
A case of yellow nail syndrome - Anaesthetic management and concerns
}

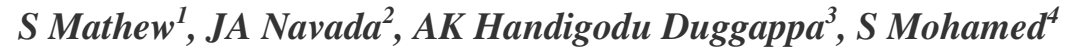 \\ Associate Professor ${ }^{1}$, Senior Resident ${ }^{2}$, Associate Professor ${ }^{3}$, Assistant Professor ${ }^{4}$ \\ Department of Anaesthesia, Kasturba Medical College, Manipal, Karnataka, India.
}

*Corresponding author: shajimanipal@yahoo.co.in

\begin{abstract}
A 19-year old patient diagnosed with yellow nail syndrome was posted for bronchoscopic examination for aspiration and clearance of secretions. There were symptoms pertaining to cardiorespiratory systems. He was uncooperative to undergo the procedure under local anaesthesia. Procedure was successfully managed using dexmedetomidine infusion.
\end{abstract}

Key words: Yellow nail syndrome; respiratory distress; bronchoscopy

\section{Introduction}

Yellow nail syndrome (YNS) is a rare condition of unknown aetiology characterized by triad of slow growing yellowish dystrophic nails $(<0.5$ $\mathrm{mm} /$ week), lymphoedema and pleural effusion. Diagnosis can be made in the presence of two of these symptoms. ${ }^{1,2}$ Distressing symptoms emerge due to the involvement of cardiorespiratory system. Many associations of the disease have been described in literature. ${ }^{1,2,3}$ Main causative factor may be morphologic and functional changes of lymph vessels. Here we share our experience of anaesthetic management of a case of YNS posted for bronchoscopy.

\section{Case report}

A 19-year old male patient diagnosed with yellow nail syndrome who presented to our hospital with fever, cough and difficulty in breathing, was scheduled for bronchoscopic clearance of secretions. Breathlessness was mild in nature to start with, which progressed in severity. Cough was moderate with difficulty in clearing the secretions. There was a history of frequent respiratory tract infections, swelling of face and lower limbs in childhood, for which he was on vitamin $\mathrm{E}$ and oral furosemide $20 \mathrm{mg}$ once daily. There was no history of any previous surgeries. Pre-anaesthetic assessment revealed a pulse rate of $100 / \mathrm{min}$ and respiratory rate $30 / \mathrm{min}$, with room air oximetry reading of $94 \%$. General examination revealed pallor, yellowish dystrophic nails, bilateral pitting pedal oedema and skin keratosis. (Figure 1, Figure 2).

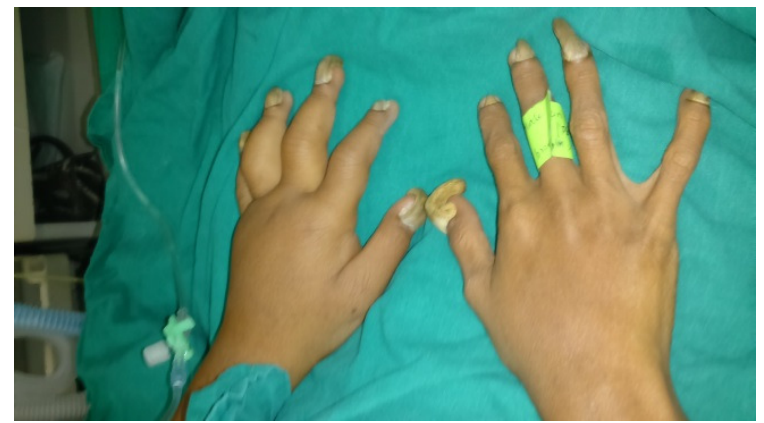

Figure 1

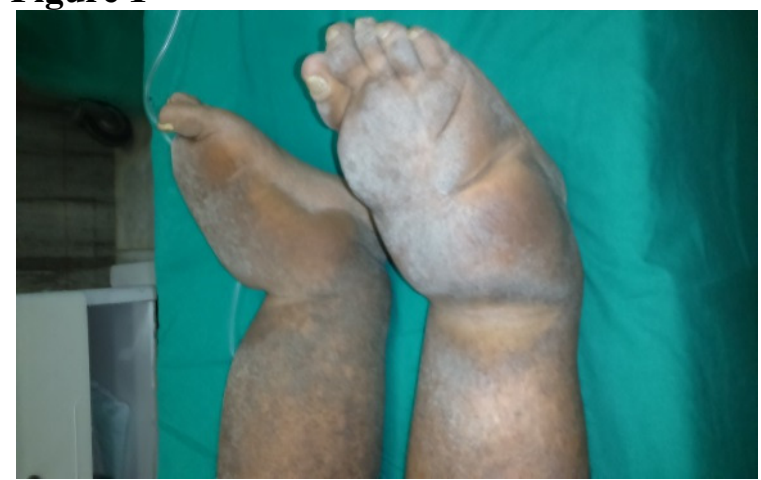

Figure 2

(c) 2017. Mathew et al. This is an Open Access article distributed under the terms of the Creative Commons Attribution License (http: //creativecommons.org/licenses/by/4. 0), which permits unrestricted use, distribution, and reproduction in any medium, provided the original work is properly credited 


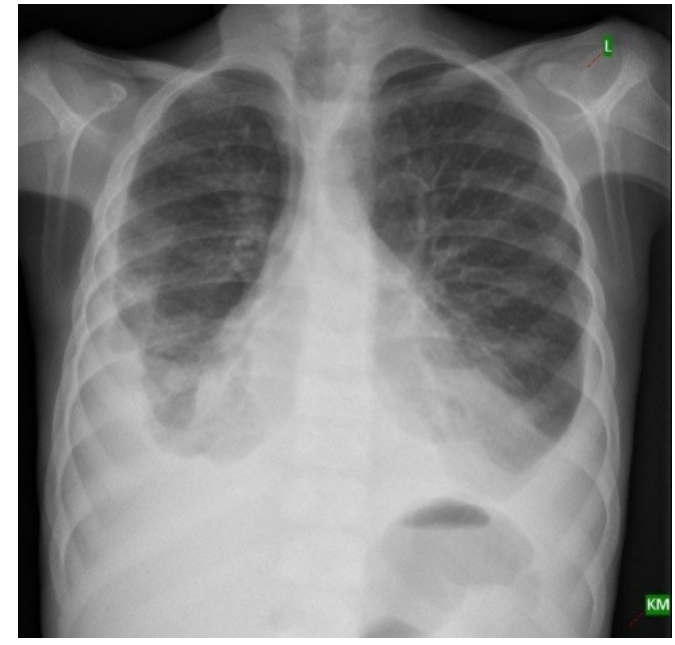

Figure 3: Chest x-ray

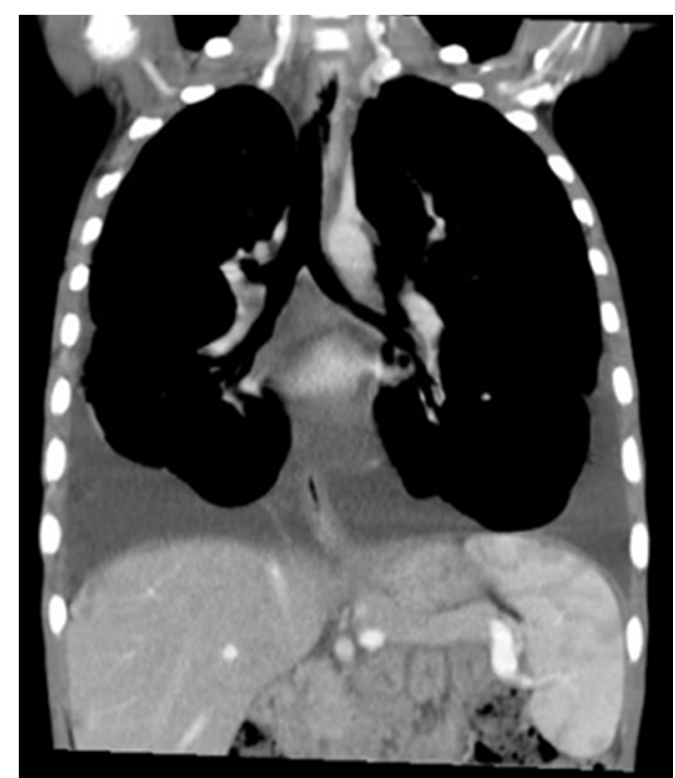

Figure 4: CT thorax

Airway assessment was conclusive of modified Mallampati class I. Cardio respiratory examination revealed grade 3 murmur best heard over apex, intercostal muscle retraction, bilateral crepitations and rhonchi. Breath sounds were reduced bilaterally more on right side. Laboratory investigations including haematocrit, renal parameters and electrolytes were normal. ECG was unremarkable, whereas in chest X-ray (Figure 3) and CT-thorax (Figure 4) bilateral pleural effusions were evident, right more than left. The findings on
2D echocardiogram were unremarkable except for the presence of mild pericardial effusion.

In premedication room, lignocaine nebulization was administered using $4 \%$ topical solution over 20 min. Once the patient was on operating table, base line monitoring was established, intravenous access secured and loading dose of dexmedetomidine $60 \mu \mathrm{g}$ administered over $10 \mathrm{~min}$ followed by an infusion of $0.5 \mu \mathrm{g} / \mathrm{kg} / \mathrm{h}$ using infusion pump. Flexible bronchoscope was introduced and $3 \mathrm{ml}$ of preservative free lignocaine was sprayed over vocal cords, which ensured smooth passage of flexible scope into trachea. Clearance of secretions was done by ENT surgeon, which was sent for microscopic examination, culture and sensitivity. Rest of the course was uneventful.

\section{Discussion}

YNS was first described by Samman and White in 1964, whereas only a few cases are reported from India. Cause may be idiopathic, familial or acquired. ${ }^{3}$ Clinical triad include dystrophic nails, respiratory involvement and lymphoedema. Lymphoedema usually affects limbs and rarely eye lids. There can be a diagnostic challenge since all three symptoms are present only in a minority of patients. Moreover spontaneous clearing of nail changes has been reported. Many clinicians believe that presence of any two symptoms are enough to establish the diagnosis. ${ }^{1,2}$ Pleuropulmonary involvement causes the most distressing symptoms, which are seen in more than $65 \%$ of cases. Respiratory tract involvement in this syndrome was in the form of rhino sinusitis, bronchiectasis, recurrent pneumonia and pleural effusion. ${ }^{4}$ Pleural effusion is usually the last clinical manifestation to appear, control of which is important to improve the quality of life..$^{5}$ Nail changes may occur in all or few digits, which includes excessive convexity, thickening, oncholysis, absence of lunules, deficient cuticles and slow rate of nail growth. Patient may have pericardial effusion and chylous ascites. Syndrome has strong association with other diseases including malignancies such as carcinomas of lung, gall bladder, breast, connective tissue disorder, mycosis fungoides, endocrine disorders, immune deficiencies and drugs such as

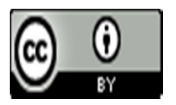

C 2017. Mathew et al. This is an Open Access article distributed under the terms of the Creative Commons Attribution License (http: //creativecommons.org/licenses/by/4. 0), which permits unrestricted use, distribution, and reproduction in any medium, provided the original work is properly credited 
d-pencillamine and bucillamine. ${ }^{3,6}$ Lung function tests may show combined obstructive and restrictive pattern with minimal reversibility. ${ }^{6}$

When GA with endotracheal intubation is mandatory, clinician needs to rule out vocal cord oedema, respiratory tract infections, and massive pleural and pericardial effusion. If an alternative to tracheal intubation is available it should be considered, owing to lymphoedematous involvement of cardiorespiratory system and hyper reactive airway in the presence of infection. No interactions are known with anaesthetic drugs. Patients with history of recent change of voice should undergo otolaryngeal examination to rule out vocal cord oedema, in whom tracheal intubation and extubation should be meticulously planned, as delayed laryngeal oedema requiring re intubation is documented in literature. Large bore venous access is preferable, which should be removed as early as possible because of generalized congenital hypoplastic lymphatics. Patients with involvement of cardiorespiratory symptoms may need HDU admission and chest physiotherapy after the procedure. Regional anaesthesia is an acceptable option whenever feasible, with a special emphasis on intravascular volume, which is likely to be depleted due to administration of diuretics. ${ }^{6}$ This group of patients can have profound hypotension after administration of central neuraxial blockade. Our patient underwent flexible bronchoscopy for clearance of secretions and aspiration of content for culture and sensitivity. Patient was uncooperative, which necessitated use of dexmedetomidine infusion for conscious sedation. Dexmedetomidine is an ideal drug for conscious sedation owing to its sedative and analgesic properties without causing respiratory depression. ${ }^{7}$

Multidisciplinary approach is needed for the diagnosis as well as anaesthetic management of this rare syndrome. Anaesthesia provider should have a basic knowledge of this entity because of the multisystem involvement and associated anaesthetic concerns.

\section{References}

1. Dixit R, Dixit K, Jindal S. Yellow nail syndrome. Lung India 2007;24:66-8. https://doi.org/10.4103/0970-2113.44214

2. Mehta Y, Vasanth V, Balachandran C. Yellow nails following hemodialysis in chronic renal failure: is it yellow nail syndrome or a variant? Dermatol Online J 2008; 14:20.

3. Maldonado F, Tazelaar HD, Wang CW. Yellow nail syndrome: Analysis of 41 consecutive patients. Chest 2008;134:375-81. https://doi.org/10.1378/chest.08-0137 PMid:18403655

4. Hiller E, Rosenow EC III, Olsen AM. Pulmonary manifestations of the yellow nail syndrome. Chest 1972;61:452-58.

https://doi.org/10.1378/chest.61.5.452

PMid:5046843

5. Araia H, Inui K, Nishiia T, Oyamab Y, Takeshitab $\mathrm{S}$, et al. A pleuroperitoneal shunt for interactive pleural effusions with yellow nail syndrome. J Med Cases.2011;2:115-120. https://doi.org/10.4021/jmc202w

6. Hershko A, Hirshberg B, Nahir M, Friedman G. Yellow nail syndrome. Postgrad Med J 1997;73:466-68. https://doi.org/10.1136/pgmj.73.862.466 PMid:9307736 PMCid:PMC2431365

7. Reves JG, Glass PS, Lubarsky DA, McEvoy MD, Martinez-Ruiz R. Miller's Anesthesia. 7th ed. USA: Churchill Livingstone Elsevier; 2010. Intravenous anesthetics; p. 719-68. 